\title{
Utility of an alternative bicycle commute route of lower proximity to motorised traffic in decreasing exposure to ultra-fine particles, respiratory symptoms and airway inflammation - a structured exposure experiment
}

\author{
Tom Cole-Hunter ${ }^{1,2}$, Rohan Jayaratne ${ }^{2}$, lan Stewart ${ }^{1}$, Matthew Hadaway ${ }^{1}$, Lidia Morawska ${ }^{2}$ and Colin Solomon ${ }^{3,4^{*}}$
}

\begin{abstract}
Background: Bicycle commuting in an urban environment of high air pollution is known to be a potential health risk, especially for susceptible individuals. While risk management strategies aimed to reduce exposure to motorised traffic emissions have been suggested, only limited studies have assessed the utility of such strategies in real-world circumstances.

Objectives: The potential to lower exposure to ultrafine particles (UFP; $<0.1 \mu \mathrm{m}$ ) during bicycle commuting by reducing proximity to motorised traffic was investigated with real-time air pollution and intermittent acute inflammatory measurements in healthy individuals using their typical higher proximity, and an alternative lower proximity, bicycle commute route.

Methods: Thirty-five healthy adults (mean \pm SD: age $=39 \pm 11 \mathrm{yr}$; 29\% female) completed two return trips, one each in the condition of their typical route $(H \mathrm{GH})$ and a pre-determined alternative route of lower proximity to motorised traffic (LOW); proximity being determined by the proportion of on-road cycle paths. Particle number concentration (PNC) and diameter (PD) were monitored in-commute in real-time. Acute inflammatory indices of respiratory symptoms (as a scalar of frequency from very low to very high / 1 to 5), lung function and spontaneous sputum (for inflammatory cell analyses) were collected immediately pre-commute, and immediately and three hours post-commute.
\end{abstract}

Results: In the condition of LOW, compared to in the condition of HIGH, there was a significant decrease in mean PNC $\left(1.91 \times e^{4} \pm 0.93 \times e^{4}\right.$ ppcc vs. $2.95 \times e^{4} \pm 1.50 \times e^{4}$ ppcc; $\left.p \leq 0.001\right)$, and the mean frequency of in-commute offensive odour detection ( 2.1 vs. $2.8 ; p=0.019$ ), dust and soot observation (1.7 vs. $2.3 ; p=0.038$ ) and nasopharyngeal irritation (1.5 vs. 1.9; $p=0.007$ ). There were no significant differences between LOW and HIGH in the commute distance and duration (12.8 \pm 7.1 vs. $12.0 \pm 6.9 \mathrm{~km}$ and $44 \pm 17$ vs. $42 \pm 17 \mathrm{~min}$, respectively), or other indices of acute airway inflammation.

Conclusions: Exposure to PNC and offensive odour, and nasopharyngeal irritation, can be significantly lowered when utilising a route of lower proximity to motorised traffic whilst bicycle commuting, without significantly affecting commute distance or duration. This may bring health benefits for both healthy and susceptible individuals.

Keywords: Air pollution, Bicycle commuting, Ultrafine particle, Respiratory symptom, Lung function, Inflammatory cell, Risk management

\footnotetext{
* Correspondence: csolomon@usc.edu.au

${ }^{3}$ School of Life Sciences, Queensland University of Technology, 2 George

Street, Brisbane, QLD 4001, Australia

${ }^{4}$ School of Health and Sport Sciences, University of the Sunshine Coast, Sippy

Downs Drive, Sippy Downs, QLD 4556, Australia

Full list of author information is available at the end of the article
} 


\section{Introduction}

The health benefits of physical activity associated with active transport are well-established [1-3], but the negative health effects of elevated air pollution exposure are also known [4-6]. Subsequently, there is evidence for causeeffect mechanisms and methods to reduce the degree of air pollution exposure whilst actively commuting [7-11]. Risk management strategies for reducing air pollution exposure whilst actively commuting can include reducing proximity to motorised traffic by avoiding main roads at peak traffic times [12]. The majority of projects on this topic have utilised micro-environments of designated offroad and on-road bicycle paths, and have determined that the former generally facilitates a significantly lower potential for exposure to air pollution, mainly from motorised traffic emissions such as ultrafine particles (UFP) [13-17]. Health indices, including acute respiratory symptoms, impaired lung function and inflammation-associated cell distribution have been used to investigate the physiological response to components of air pollution including particle number concentrations (PNC; which is dominated by UFP) [18-20].

Additionally, questionnaires that assess the influence of air pollution exposure on the airways have been used previously [21-24], using specific symptoms attributable to acute air pollution exposure as recommended by the American Thoracic Society [25]. For example, airway narrowing due to inflammation and excessive mucous secretion (as an immune response to airway irritation by pollutants) can induce coughing and chest tightness or wheezing, as well as reduce lung function indicated by lowered peak expiratory flow rates [26]. Further, an increase in the number of leukocytes, and specifically neutrophils, found in the airways and systemic circulation can indicate an inflammatory response to exposure from air pollutants such as ultrafine particles [27,28]. However, the utility by bicycle commuters of an informed alteration to their own typical route to avoid major motorised traffic corridors, and consequently reduce exposure to elevated $\mathrm{PNC}$, and thereby decrease any associated negative health effects, is yet to be investigated.

Bicycle commuters may not have a route which allows complete use of off-road bicycle paths. Therefore, it is not expected to be practical for a bicycle commuter to completely alter their commute route and completely avoid exposure to motorised traffic emissions, particularly those due to factors such as road crossings that dissect off-road paths. However, it is possible, and may be practical, to decrease exposure to UFP by selecting a route which has reduced proximity to motorised traffic. Therefore, for this experiment it was hypothesised that: 1) a route alteration designed to lower proximity to motorised traffic during bicycle commuting will significantly reduce exposure to combustion emissions [represented by the dominant ultrafine particle (UFP; $<0.1 \mu \mathrm{m}$ ) number concentration (PNC)], compared to a high proximity route; 2 ) health outcomes, including incidence and severity of acute respiratory symptoms, peak flow rate, and cell distribution in sputum, will be improved with the use of a route of lower proximity to motorised traffic, compared to a route of high proximity; 3) the difference in the estimated inhaled PNC between the two routes will be attributable to the difference in ambient UFP, rather than any difference in physical effort (indicated by heart and ventilation rate).

\section{Methods}

\section{Project design}

This project was designed to determine whether the use of an alternative bicycle commute route designed to lower proximity to motorised traffic (and therefore lower exposure to associated emissions) is practical as an exposure risk management strategy. Thirty-five healthy adults were recruited to perform their typical workday commute along both their typical route (deemed as of high proximity to motorised traffic; termed HIGH) and an altered route (designed to be of lower proximity to motorised traffic; termed LOW). The participants and their bicycles were instrumented to measure real-time exposure variables of geolocation, heart rate, and particle number concentration and diameter while in-commute. Participants performed a selection of physiological inflammatory response tests immediately pre-commute, immediately post-commute and three hours post-commute to relate these outcomes to in-commute exposure variables. This project was approved by the Queensland University of Technology Human Research Ethics Committee. Prior to participation in this project, written informed consent was provided by participants.

\section{Participants}

The participants of this project were healthy adults $(\mathrm{n}=35$; $29 \%$ female. Mean \pm SE: age $=39 \pm 11$ yr, PFR $=558 \pm$ 105 L-min) with no history of cardiopulmonary disease and no recent history of smoking (cessation $>$ twenty-four months prior) or respiratory infection (symptoms $>$ two weeks prior). Participants were required to be frequent bicycle commuters of the Brisbane inner-city region [defined as completing two or more return trips in a five day period to a destination within a $1 \mathrm{~km}$ radius of the Brisbane Central Business District (CBD)] and have a typical commute route of high proximity to motorised traffic. Recruitment was conducted from participants who provided consent as part of a previous study [22], and eligible respondents to a regional media release. Participants were requested to avoid any air pollution sources where possible, such as second-hand smoke and traffic congestion during the pre-commute and three hour post-commute monitoring period. This request may have affected a 
participant's typical activity and exposure, however it was included to concentrate any acute inflammatory response to the in-commute exposure.

\section{Project locality}

Brisbane is the state capital of Queensland, and the third largest city in Australia. The Brisbane CBD is located at $27^{\circ} 3^{\prime}$ South, $153^{\circ} 9^{\prime}$ East, approximately $20 \mathrm{~km}$ inland from the Pacific Ocean. Brisbane is located in a lowlying floodplain, with several large hills of up to 300 metres in height within the area, bordered to the west by a coastal mountain range. A large river runs through the city area. The regional climate is sub-tropical, being cool and dry in winter (between June to August), and humid and wet in summer (between December to February) [29]. The city of Brisbane has a population of approximately two million people, which has been increasing annually by approximately two percent for the last two decades [30]. Motorised traffic volume, along with population growth, is rapidly increasing, particularly due to outer-city residential development [30]. The number of motor vehicles registered within Brisbane in 2011 was approximately one million, however the greater region of South-East Queensland includes a total of nearly three million [31]. Industrial air pollution sources include a major airport, seaport, and oil refineries (all approximately $15 \mathrm{~km}$ north-east of the CBD), a coal power station (approximately $30 \mathrm{~km}$ south-west of the CBD), and various manufacturing companies in the outer suburbs.

\section{Routes of high and low proximity to motorised traffic}

The participants typical commute route, which had been selected due to it being more than two-thirds on-road cycle path, was used as the high proximity to motorized traffic (HIGH) route. Participants, in consultation with the primary investigator, determined the altered route of lower proximity to motorised traffic (LOW) based on their typical bicycle commute route. Each participant rode a return trip [inbound (morning) and outbound (evening)] of each of HIGH and LOW on consecutive days. An equal number of participants performed HIGH or LOW first, to counterbalance and negate any influence of the order of the route condition. Therefore, a total of 140 trips were performed as a result of 35 participants each completing an inboundHIGH, outbound-HIGH, inbound-LOW and outboundLOW trip. Following the completion of these two return trips, participants were asked which route (HIGH or LOW) they preferred and to rate the importance of specific components (with examples) such as fitness (e.g. longer training session), health (e.g. to avoid air pollution), safety (e.g. greater riding space / visibility), social (e.g. group commute / drink stop) and time (e.g. more convenient / quickest route) each on a five-grade scale ( 1 = Very low, 2 = Low, 3 = Moderate, 4 = High, 5 = Very high).

\section{In-commute particle concentration and diameter}

To measure and record real-time PNC and diameter (PD) both in-commute and three hours post-commute, an Aerasense NanoTracer (Philips, The Netherlands) with a 16-second logging frequency was carried by each participant. The sampling tube of the NanoTracer was attached to the participant in their immediate breathing zone, for example on their shirt collar or upper backpack strap. The NanoTracer is a compact and portable device capable of measuring PNC (0 - $\mathrm{e}^{6}$ particles per cubic centimeter (ppcc)) and PD $(0.01-0.3 \mu \mathrm{m})$ in real-time via diffusion charging [32]. The NanoTracer does not experience tilt errors that may be produced with fluid-reliant instruments (such as a condensation particle counter) during vigorous use (such as for active transport monitoring); therefore, this device has potential for application in the field, which has been shown through previous research [33]. In-commute PNC and PD means, medians and range were calculated with NanoReporter software (Philips, The Netherlands). Individual device correction factors of $0.75,0.99$ and 1.30 for each of the three NanoTracers used were determined by laboratory testing at the International Laboratory for Air Quality and Health (ILAQH) using a condensation particle counter (CPC 3787, TSI) in atmospheric air (at a university campus location 200 metres from a main highway with four traffic lanes in each direction) for 4 hours. PNC and PD means below 100 ppcc and $0.01 \mu \mathrm{m}$, respectively, or that changed by more than a factor of 10 at subsequent readings, are considered to be invalid and thus were removed from initial particle measurement data prior to analyses $[10,34]$. The NanoTracer is factory-calibrated, so any attempt of self-calibration was not possible (due to risk of warranty nullification) and was beyond the scope of this study.

\section{In-commute heart rate}

Heart rate $\left(\mathrm{F}_{\mathrm{H}}\right)$ was monitored, both in-commute and for three hours post-commute, using a telemetry unit (Polar Electro, Finland) logging at five second intervals. In-commute $\mathrm{F}_{\mathrm{H}}$ was compared between $\mathrm{HIGH}$ and LOW to determine if there was a difference in physical effort when performing the two routes and therefore indicate if an inhaled particle count is affected most by the PNC in the air or the ventilation rate for the two routes. As an individual's $\mathrm{F}_{\mathrm{H}}$ and ventilation rate are associated [35], a higher mean trip $\mathrm{F}_{\mathrm{H}}$ would produce a higher mean trip ventilation rate and therefore a higher total number of inhaled particles at any PNC.

\section{Climate}

The Australian Bureau of Meteorology Climate Database [29] was accessed for hourly regional measures of temperature, humidity, wind direction and speed, air pressure, and precipitation. Meteorological data was collated and 
analysed to explain any particle measurement differences between commute monitoring days due to different atmospheric conditions.

\section{Physiological inflammatory responses}

The participants performed three self-administered tests (as symptom reporting, peak flow metering and sputum collecting) to assess the manifestation of an acute biological inflammatory response attributable to air pollution exposure. A verbal and written explanation of instructions for each test was provided to participants at an induction session. Symptoms and peak flow rates were measured immediately pre-commute and postcommute, and three hours post-commute either at the participant's home or workplace. Sputum samples were collected immediately pre-commute and three hours post-commute only. See Additional files 1 and 2 for written instructions and symptom questionnaire provided to participants.

\section{Symptom questionnaire}

At the induction, participants were supplied with a questionnaire (produced using information from the American Thoracic Society [25]) to report the incidence and severity of specific signs and symptoms including offensive odour detection (and dust or soot observation), eye, nose and throat irritation, coughing and/or phlegm production, chest tightness and/or wheezing, on a five-grade scale $(1=$ Very Low, 2 = Low, $3=$ Moderate, $4=$ High, and $5=$ Very High). The same questions were used for each time period of immediately pre-commute, immediately postcommute, and three hours post-commute to attribute symptoms to air pollution data of each monitored commute trip.

\section{Peak expiratory flow rates}

At the induction, participants were supplied with a peak flow meter (MicroPeak, CareFusion, UK) and disposable one-way mouthpieces. Participants were instructed to perform and record three peak flow maneuvers (to obtain a mean value) at the end of each time period of immediately pre-commute, immediately post-commute, and three hours post-commute to relate peak flow changes to air pollution data of each monitored trip. The standard deviations of peak flow rates were examined to evaluate reproducibility of the forced expiratory manoeuvre.

\section{Sputum sampling and cell counts}

At the induction, participants were supplied with plastic (Falcon) tubes $(15 \mathrm{~mL})$ containing $2 \mathrm{~mL}$ of an RNA collection solution (RNAlater), the relevant RNAlater material safety data sheet, and instructions for spontaneous sputum production. Approximately
$2 \mathrm{~mL}$ of sputum was collected in the RNAlater and immediately refrigerated at approximately $4^{\circ} \mathrm{C}$ by participants, and then frozen at $-20^{\circ} \mathrm{C}$ within $24-$ hours by investigators for later analysis.

For total cell counts, the sputum samples were removed from the $-20^{\circ} \mathrm{C}$ freezer and thawed, then centrifuged for $15 \mathrm{~min}$ at $500 \mathrm{x}$ g at $25^{\circ} \mathrm{C}$. The supernatant was removed and the cell pellet maintained, then $2 \mathrm{~mL}$ of PBS was added to suspend the cells and the sample was briefly vortexed. The cell suspension was aliquoted $(2 \times 10 \mu \mathrm{L})$ in to the haemocytometer slide wells, and then viewed at $\times 40$ magnification (Olympus light microscope). Satisfactory total cell counts were completed by one blinded counter. The proportion of squamous epithelial cells (SECs) was determined to indicate validity via saliva contamination (by $\leq 400$ SECs per 100 leukocytes) of each sputum sample.

For differential cell counts, a $200 \mu \mathrm{L}$ aliquot of cell suspension was cytospun ( $5 \mathrm{~min}$ at $100 \mathrm{x} \mathrm{g}$ ), fixed with methanol, stained (Rapid Diff) and mounted (Permount) with a cover-slip, and then viewed at x100 magnification (Olympus light microscope). Satisfactory differential cell counts (from 2 slides with $>50 \%$ viability and $<75 \%$ SECs, 100 non-SECs per slide) were completed by one blinded counter.

Cell count reference values of eosinophils, lymphocytes, macrophages and neutrophils in induced sputum of healthy adults were consulted to inform validation of sample quality [36].

\section{Statistical data analysis}

Due to the expected variation of typical commute characteristics (including commute time, distance and duration) within the participant group, the in-commute trip variable means (as well as medians for PNC and $\mathrm{PD}$ ) of the four different individual data sets (i.e. both inbound and outbound trips of HIGH and LOW) of a single participant were initially compared. Subsequently, means (or medians for PNC and PD) of both inbound and outbound trips of HIGH and LOW were compared to determine the utility of a bicycle commute route alteration to lower exposure to motorised trafficemitted ultrafine particles. All analyses were performed with predictive analytics software (PASW v18.0; IBM, New York).

Estimated marginal means of personal factors and factors of exposure, along with descriptive values, were produced. Pearson bivariate correlations were performed for particle measurements (PNC, PD) with independent variables of meteorology, symptoms and age. Pearsons bivariate correlations were also performed between CBD proximity (indicative of general proximity to motorised traffic) and HIGH and LOW data for PNC, PD and heart rate. Multivariate 
repeated measure ANOVA was performed with the mean and median of the dependent variables of PNC and PD for both inbound and outbound conditions of HIGH and LOW to determine intra-individual variability. One-way ANOVA, and Tukey Post-Hoc tests, where applicable, were performed with PNC, PD (as independent variables), gender and the dependent variable symptom reporting, each at the three different time-points. Mixed Effects Models analysis was performed with PNC, PD and participant symptom reporting, lung function and cell counts to determine the effect of particles on the physiological inflammatory response between inbound and outbound in HIGH and LOW. Mixed Effects Model analysis was performed to determine the difference between the three timepoints within each commute condition (i.e. immediately pre-commute, immediately post-commute and three-hours post-commute) in relation to in-commute PNC and PD. Statistical significance was accepted at $\mathrm{P}<0.05$.

\section{Results}

\section{Bicycle commute characteristics}

Due to the regional location of the bicycle paths, it was not practically possible to produce exactly the same proportion of off-road paths for each participant; therefore, as expected, there was a range in the distribution of path type within HIGH and LOW. For example, popular south and west LOW routes were adjacent to, but physically-separated from, two different major motorised traffic corridors and therefore had lower proportions of off-road paths. Conversely, popular north and east LOW routes ran adjacent to parklands and a major river, respectively, facilitating higher proportions of off-road paths.

\section{In-commute particle measurements}

The mean commute PNC for LOW was significantly lower than HIGH $\left[1.91 \times \mathrm{e}^{4} \pm 0.93 \times \mathrm{e}^{4}\right.$ vs. $2.95 \times \mathrm{e}^{4} \pm$ $1.50 \times \mathrm{e}^{4}$ ppcc; F-statistic (degrees of freedom) and p-value: $F(1,35)=21.079$ and $p \leq 0.001]$, and the mean commute PNC within HIGH was significantly higher for inbound compared to outbound trips $[\mathrm{F}(1,35)=$ 8.441; $\mathrm{p}=0.007]$. See Table 1. The median commute PNC for LOW was significantly lower than HIGH $\left[1.36 \times \mathrm{e}^{4} \pm 0.73 \times \mathrm{e}^{4}\right.$ vs. $1.99 \times \mathrm{e}^{4} \pm 1.05 \times \mathrm{e}^{4}$ ppcc; $\mathrm{F}(1,35)=14.025 ; \mathrm{p}=0.001]$, however there was no significant difference between LOW or HIGH inbound and outbound trips $(\mathrm{p}>0.10)$. See Table 1.

The median commute PD was not significantly different between HIGH and LOW, or between HIGH or LOW inbound and outbound trips $(\mathrm{p}>0.08$ ). See Table 1 . Mean PNC and PD were negatively-correlated $(r=-0.645$; $\mathrm{p}=0.048)$.

\section{Commute distance, duration, speed and heart rate}

The mean commute distance and duration, and therefore commute speed, were not significantly different between HIGH and LOW [12.0 \pm 6.9 vs. $12.8 \pm 7.1 \mathrm{~km}$ ( $\mathrm{p}>0.10)$ and $42 \pm 17$ vs. $44 \pm 17 \mathrm{~min}(\mathrm{p}>0.10), 17.0 \pm$ 4.6 vs. $17.1 \pm 4.7 \mathrm{~km} / \mathrm{hr}(\mathrm{p}>0.10)]$, or between HIGH or LOW inbound and outbound trips. See Table 1. The mean commute heart rate were not significantly different between HIGH and LOW, or between HIGH or LOW inbound and outbound trips, ( $\mathrm{p}>0.10)$. See Table 1.

Table 1 Commute variables for routes of high (HIGH) and low (LOW) proximity to motorised traffic; direction

\begin{tabular}{|c|c|c|c|c|}
\hline \multirow[t]{2}{*}{ Condition } & \multicolumn{2}{|c|}{$\mathrm{HIGH}$} & \multicolumn{2}{|c|}{ LOW } \\
\hline & Inbound & Outbound & Inbound & Outbound \\
\hline Time (24:00) & $8: 20 \pm 0: 22$ & $16: 39 \pm 0: 23$ & $8: 04 \pm 0: 22$ & $16: 33 \pm 0: 23$ \\
\hline Distance (km) & $12.3 \pm 6.9$ & $11.7 \pm 6.9$ & $12.9 \pm 7.2$ & $12.6 \pm 7.0$ \\
\hline Duration (min) & $42 \pm 18$ & $41 \pm 15$ & $45 \pm 17$ & $43 \pm 16$ \\
\hline Speed $\left(\mathrm{km} \cdot \mathrm{hr} r^{-1}\right)$ & $17.3 \pm 4.3$ & $16.7 \pm 4.8$ & $17.1 \pm 4.6$ & $17.1 \pm 4.7$ \\
\hline Heart Rate (bpm) & $137 \pm 11$ & $135 \pm 11$ & $134 \pm 9$ & $131 \pm 9$ \\
\hline Temperature $\left({ }^{\circ} \mathrm{C}\right)$ & $17.9 \pm 3.5$ & $21.1 \pm 3.0^{\# \#}$ & $17.7 \pm 3.5$ & $21.5 \pm 3.2^{\# \#}$ \\
\hline Humidity (\%) & $61 \pm 14$ & $48 \pm 19^{\# \#}$ & $62 \pm 13$ & $49 \pm 19^{\# \#}$ \\
\hline Wind Speed $\left(\mathrm{km} \cdot \mathrm{hr}^{-1}\right)$ & $5.8 \pm 3.2$ & $9.5 \pm 4.8$ & $7.1 \pm 3.2$ & $8.5 \pm 4.4$ \\
\hline Air Pressure (hPa) & $1019 \pm 6$ & $1016 \pm 5$ & $1019 \pm 6$ & $1016 \pm 5$ \\
\hline PNC Mean ( $x e^{4} ;$ ppcc) & $3.30 \pm 1.57$ & $2.60 \pm 1.35^{\# \#}$ & $1.99 \pm 1.02^{* *}$ & $1.84 \pm 0.84^{* *}$ \\
\hline PNC Median ( $x e^{4} ;$ ppcc) & $2.20 \pm 1.02$ & $1.77 \pm 1.08$ & $1.34 \pm 0.79^{* *}$ & $1.38 \pm 0.67^{* *}$ \\
\hline PD Median (nm) & $49 \pm 10$ & $47 \pm 8$ & $52 \pm 11$ & $50 \pm 11$ \\
\hline
\end{tabular}

Values are means (or median where indicated) \pm standard deviation. Significance [from multivariate repeated measure ANOVA]: ${ }^{*} \mathrm{p}<0.05,{ }^{* *} \mathrm{p}<0.01$ compared to $\mathrm{HIGH} ; \mathrm{p}<0.05,{ }^{\# \#} \mathrm{p}<0.01$ compared to Inbound. PNC (ppcc) = particle number concentration (particles per cubic centimetre), PD = particle diameter. 


\section{Climate}

All meteorological variables were not significant different between HIGH and LOW (Data not presented, $\mathrm{p}>0.10$ ). Due to natural diurnal variation, the mean inbound (morning) commute temperature was significantly lower $[\mathrm{F}(1,35)=$ 47.085; $\mathrm{p} \leq 0.001$ ] and the humidity significantly higher $[\mathrm{F}(1,35)=54.114 ; \mathrm{p} \leq 0.001]$, compared to the outbound (afternoon) trip. See Table 1.

Mean commute temperature was negatively-correlated with PNC ( $\mathrm{r}=-0.83 ; \mathrm{p}=0.005)$ and positively-correlated with PD $(\mathrm{r}=0.79 ; \mathrm{p}=0.014)$. Mean commute humidity was not significantly correlated with mean PNC or PD (both with $\mathrm{r}<0.40 ; \mathrm{p}>0.10$ ). Regional wind direction was not correlated to particle measurements $(\mathrm{r}<0.40$; $\mathrm{p}>0.10)$, but general wind speed was negatively-correlated to PNC $(\mathrm{r}=-0.77 ; \mathrm{p}=0.018)$ and $\mathrm{PD}(\mathrm{r}=-0.74 ; \mathrm{p}=0.021)$.

\section{Inflammatory response}

\section{Air quality detection and symptoms}

The means for the specific detection and symptoms variables for LOW were significantly lower than HIGH for offensive odour detection $[2.1 \pm 0.5$ vs. $2.8 \pm 0.8$ : $F(1,406)=$ $5.515 ; \mathrm{p}=0.019]$, dust and soot observation [1.7 \pm 0.3 vs. $2.3 \pm 0.5: \mathrm{F}(1,140)=4.340 ; \mathrm{p}=0.038]$, nasal and throat irritation $[1.5 \pm 0.3$ vs. $1.9 \pm 0.2: \mathrm{F}(1,140)=7.266 ; \mathrm{p}=$ 0.007]. All other specific acute respiratory symptoms were not significantly different between HIGH and LOW $(\mathrm{p}>0.10)$.

Offensive odour, and dust or soot, detection was significantly higher for both HIGH and LOW in-commute, compared to pre-commute and post-commute, $[\mathrm{F}(1,406)=$ $4.165 ; \mathrm{p}<0.031$ ]. See Table 2. Nasal and throat irritation was significantly higher only for HIGH immediatelypost-commute, compared to HIGH pre-commute and three-hour-post-commute, $[\mathrm{F}(1,140)=7.545 ; \mathrm{p}<$ 0.006]. See Table 2.

The means for detection and symptoms in-commute, compared to pre-commute and post-commute, were significantly higher for offensive odour detection ( $\mathrm{p} \leq 0.001$ ), dust or soot detection ( $\mathrm{p} \leq 0.001)$, eye irritation ( $\mathrm{p} \leq 0.001$ ), nasal irritation ( $\mathrm{p} \leq 0.001)$; throat irritation ( $\mathrm{p} \leq 0.001)$; phlegm production ( $\mathrm{p} \leq 0.001)$; and, chest tightness $(\mathrm{p}=$ 0.003 ). Cough and chest wheeze were significantly higher for in-commute $\mathrm{p}=0.012,0.017$, respectively), but not the post-commute time period ( $\mathrm{p}=0.070,0.176$, respectively), compared to the pre-commute time period.

Participant age was positively-correlated with immediately-post-commute throat irritation $(r=0.78 ; \mathrm{p}=0.049)$ and phlegm production $(\mathrm{r}=0.83 ; \mathrm{p}=0.024)$. Female participants, compared to males, reported significantly higher immediately-post-commute throat irritation (1.57 \pm 0.88 versus $1.33 \pm 0.68 ; \mathrm{p} \leq 0.001)$ and headache $(1.14 \pm 0.49$ versus $1.06 \pm 0.35 ; \mathrm{p}=0.005)$. No other participant characteristics were associated with these symptoms.

\section{Peak flow rate}

Peak flow rate was not significantly different within HIGH or LOW from pre-commute to immediately or three hours post-commute ( $\mathrm{p}>0.10$ ) or, between HIGH and LOW post-commute. Female, compared to male, participants had a significantly lower mean peak flow rate across all conditions ( $447 \pm 66$ versus $584 \pm 89 \mathrm{~L} \cdot \mathrm{min}$; $\mathrm{p} \leq 0.001$ ). The mean intra-individual difference (and standard deviation) between PFR performance was $20.3 \pm 11.3 \mathrm{~L} \cdot \mathrm{min}$. See Table 2.

\section{Sputum cell counts}

Total and differential cell counts of valid sample sets [when compared to other values of healthy adults (35), 22 of 35;63\%] were not significantly different between LOW and HIGH, or between pre-commute and three hours post-commute. Specifically, there was no significant difference in neutrophil counts in HIGH three hours post-commute compared to in HIGH pre-commute, or in LOW three hours post-commute ( $p>0.10)$. See Table 3. There was no correlation between neutrophil count and in-commute PNC or PD ( $r<0.40$; $\mathrm{p}>$ $0.10)$.

\section{Route preference and importance of components}

Two-thirds of participants (23 of 35; 66\%) preferred LOW compared to HIGH. For this preference, the components (in decreasing order by mean rating of importance) were safety (as a mean rating out of 5 , and the standard deviation of the mean; $3.86 \pm 0.19)$, health (3.06 \pm 0.09$)$, fitness $(2.34 \pm 0.11)$ and social $(1.31 \pm 0.20)$. Twelve participants (12 of 35 ; 34\%) preferred HIGH compared to LOW, indicating the most important component as being time $(3.63 \pm 0.12)$.

\section{Discussion}

The results of this project indicate that an informed route alteration designed to lower proximity to motorised traffic during bicycle commuting does significantly reduce exposure to combustion emissions (represented by PNC), as well as offensive odours, dust and soot. The route alteration does not affect factors of utility such as commute distance or duration. There was an increase in nasal and throat irritation, but no physiological inflammatory response for $\mathrm{HIGH}$, compared to LOW, proximity to motorised traffic. It can be inferred that potential inhaled PNC is attributable predominantly to a difference in ambient PNC rather than a difference in heart rate or physical effort, and thus ventilation rate, or alternative routes.

\section{In-commute particle measurements}

The exposure risk minimisation strategy of lowering proximity to motorised traffic while bicycle commuting has 
Table 2 Symptom and peak flow variables for routes of high (HIGH) and low (LOW) proximity to motorised traffic; direction and time

\begin{tabular}{|c|c|c|c|c|c|c|c|c|c|c|c|c|}
\hline \multirow[t]{3}{*}{ Condition } & \multicolumn{6}{|c|}{ HIGH } & \multicolumn{6}{|c|}{ LOW } \\
\hline & \multicolumn{3}{|c|}{ Inbound } & \multicolumn{3}{|c|}{ Outbound } & \multicolumn{3}{|c|}{ Inbound } & \multicolumn{3}{|c|}{ Outbound } \\
\hline & Pre & In & Post & Pre & In & Post & Pre & In & Post & Pre & In & Post \\
\hline Offensive Odour & $1.09 \pm 0.12$ & $2.71^{*, \# \#} \pm 0.73$ & $1.21 \pm 0.15$ & $1.12 \pm 0.13$ & $2.88^{*, \# \#} \pm 0.83$ & $1.06 \pm 0.11$ & $1.18 \pm 0.13$ & $2.06^{\# \#} \pm 0.42$ & $1.09 \pm 0.15$ & $1.18 \pm 0.14$ & $2.18^{\# \#} \pm 0.48$ & $1.09 \pm 0.11$ \\
\hline Dust, Soot & $1.06 \pm 0.11$ & $2.35^{*, \# \#} \pm 0.55$ & $1.06 \pm 0.11$ & $1.06 \pm 0.11$ & 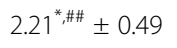 & $1.03 \pm 0.12$ & $1.18 \pm 0.14$ & $1.65^{\#} \pm 0.27$ & $1.06 \pm 0.11$ & $1.15 \pm 0.13$ & $1.65^{*, \# \#} \pm 0.27$ & $1.09 \pm 0.21$ \\
\hline Eye Irritation & $1.06 \pm 0.11$ & $1.56 \pm 0.24$ & $1.06 \pm 0.11$ & $1.18 \pm 0.14$ & $1.65 \pm 0.27$ & $1.06 \pm 0.10$ & $1.18 \pm 0.10$ & $1.26 \pm 0.16$ & $1.09 \pm 0.12$ & $1.18 \pm 0.14$ & $1.35 \pm 0.18$ & $1.06 \pm 0.12$ \\
\hline Nose Irritation & $1.38 \pm 0.19$ & $1.82^{* *} \pm 0.33$ & $1.24 \pm 0.15$ & $1.24 \pm 0.16$ & $1.74 \pm 0.30$ & $1.12 \pm 0.13$ & $1.24 \pm 0.15$ & $1.53 \pm 0.23$ & $1.12 \pm 0.13$ & $1.09 \pm 0.12$ & $1.38 \pm 0.19$ & $1.12 \pm 0.13$ \\
\hline Throat Irritation & $1.56 \pm 0.24$ & $2.00^{* *} \pm 0.40$ & $1.41 \pm 0.19$ & $1.35 \pm 0.18$ & $2.09 \pm 0.44$ & $1.26 \pm 0.16$ & $1.38 \pm 0.19$ & $1.56 \pm 0.24$ & $1.26 \pm 0.16$ & $1.24 \pm 0.15$ & $1.56 \pm 0.25$ & $1.35 \pm 0.18$ \\
\hline Cough & $1.32 \pm 0.17$ & $1.62 \pm 0.26$ & $1.32 \pm 0.17$ & $1.18 \pm 0.14$ & $1.71 \pm 0.29$ & $1.41 \pm 0.20$ & $1.29 \pm 0.17$ & $1.26 \pm 0.16$ & $1.26 \pm 0.20$ & $1.24 \pm 0.16$ & $1.35 \pm 0.19$ & $1.24 \pm 0.15$ \\
\hline Phlegm & $1.26 \pm 0.16$ & $1.97 \pm 0.38$ & $1.26 \pm 0.16$ & $1.18 \pm 0.15$ & $1.94 \pm 0.38$ & $1.35 \pm 0.18$ & $1.47 \pm 0.22$ & $1.74 \pm 0.30$ & $1.21 \pm 0.15$ & $1.29 \pm 0.17$ & $1.76 \pm 0.31$ & $1.24 \pm 0.13$ \\
\hline Chest Tightness & $1.12 \pm 0.13$ & $1.35 \pm 0.18$ & $1.09 \pm 0.12$ & $1.09 \pm 0.13$ & $1.47 \pm 0.22$ & $1.12 \pm 0.13$ & $1.09 \pm 0.12$ & $1.12 \pm 0.13$ & $1.12 \pm 0.11$ & $1.12 \pm 0.13$ & $1.15 \pm 0.13$ & $1.12 \pm 0.13$ \\
\hline Chest Wheeze & $1.03 \pm 0.11$ & $1.24 \pm 0.15$ & $1.09 \pm 0.12$ & $1.06 \pm 0.11$ & $1.26 \pm 0.16$ & $1.15 \pm 0.13$ & $1.09 \pm 0.13$ & $1.09 \pm 0.12$ & $1.09 \pm 0.13$ & $1.06 \pm 0.11$ & $1.15 \pm 0.11$ & $1.09 \pm 0.19$ \\
\hline Headache & $1.09 \pm 0.12$ & $1.21 \pm 0.16$ & $1.12 \pm 0.13$ & $1.12 \pm 0.14$ & $1.29 \pm 0.17$ & $1.09 \pm 0.12$ & $1.18 \pm 0.14$ & $1.09 \pm 0.13$ & $1.12 \pm 0.16$ & $1.18 \pm 0.14$ & $1.18 \pm 0.14$ & $1.03 \pm 0.11$ \\
\hline PFR $(\% \Delta)$ & $0.00 \pm 0.00$ & $1.28 \pm 0.16$ & $1.18 \pm 0.14$ & $0.00 \pm 0.00$ & $1.65 \pm 0.27$ & $1.63 \pm 0.27$ & $0.00 \pm 0.00$ & $1.76 \pm 0.31$ & $1.41 \pm 0.20$ & $0.00 \pm 0.00$ & $2.38 \pm 0.57$ & $2.14 \pm 0.46$ \\
\hline
\end{tabular}

Values are mean \pm standard deviation. Significance [from linear mixed models]: ${ }^{*} \mathrm{p}<0.05,{ }^{* *} \mathrm{p}<0.01$ compared to LOW; ${ }^{*} \mathrm{p}<0.05$, ${ }^{\# \#} \mathrm{p}<0.01$ compared to Pre. Direction is the return component of bicycle commute trip performance: Inbound = morning, ingress of CBD; Outbound = afternoon, egress of CBD. Time is the period relative to bicycle commute trip performance: Pre $=$ immediately pre-commute; In $=$ immediately-postcommute; Post $=$ three hours post-commute. PFR = Peak flow rate. Values are given as mean, on a scale of incidence from 1 (very low) to 5 (very high). PFR is expressed as the percentage change from Pre values. 
Table 3 Total and differential cell counts for routes of high (HIGH) and low (LOW) proximity to motorised traffic; direction and time

\begin{tabular}{|c|c|c|c|c|c|c|c|c|}
\hline \multirow[t]{3}{*}{ Condition } & \multicolumn{4}{|c|}{ HIGH } & \multicolumn{4}{|c|}{ LOW } \\
\hline & \multicolumn{2}{|c|}{ Inbound } & \multicolumn{2}{|c|}{ Outbound } & \multicolumn{2}{|c|}{ Inbound } & \multicolumn{2}{|c|}{ Outbound } \\
\hline & Pre & Post & Pre & Post & Pre & Post & Pre & Post \\
\hline Leukocyte ( $x \mathrm{e}^{6}$ cells $\cdot \mathrm{mL}^{-1}$ ) & $1.36 \pm 0.42$ & $1.38 \pm 0.43$ & $1.23 \pm 0.38$ & $1.28 \pm 0.39$ & $1.40 \pm 0.43$ & $1.37 \pm 0.42$ & $1.44 \pm 0.45$ & $1.44 \pm 0.45$ \\
\hline Epithelial $\left(x e^{6}\right.$ cells $\left.\cdot \mathrm{mL}^{-1}\right)$ & $1.16 \pm 0.30$ & $1.19 \pm 0.31$ & $1.05 \pm 0.27$ & $1.10 \pm 0.28$ & $1.20 \pm 0.31$ & $1.17 \pm 0.30$ & $1.23 \pm 0.32$ & $1.23 \pm 0.30$ \\
\hline Columnar $\left(x e^{6}\right.$ cells $\left.m L^{-1}\right)$ & $0.58 \pm 0.18$ & $0.59 \pm 0.18$ & $0.53 \pm 0.16$ & $0.55 \pm 0.17$ & $0.60 \pm 0.19$ & $0.59 \pm 0.15$ & $0.62 \pm 0.22$ & $0.62 \pm 0.21$ \\
\hline Squamous ( $x \mathrm{e}^{6}$ cells $\cdot \mathrm{mL}^{-1}$ ) & $0.78 \pm 0.30$ & $0.79 \pm 0.31$ & $0.70 \pm 0.27$ & $0.73 \pm 0.28$ & $0.80 \pm 0.31$ & $0.78 \pm 0.20$ & $0.82 \pm 0.29$ & $0.82 \pm 0.30$ \\
\hline Macrophage (\%) & $59 \pm 18$ & $58 \pm 18$ & $59 \pm 18$ & $59 \pm 18$ & $59 \pm 18$ & $59 \pm 20$ & $58 \pm 17$ & $59 \pm 18$ \\
\hline Lymphocyte (\%) & $1.4 \pm 0.4$ & $1.5 \pm 0.5$ & $0.8 \pm 0.3$ & $0.9 \pm 0.3$ & $0.8 \pm 0.2$ & $1.3 \pm 0.5$ & $1.0 \pm 0.3$ & $1.0 \pm 0.4$ \\
\hline Neutrophil (\%) & $39 \pm 12$ & $40 \pm 12$ & $40 \pm 12$ & $40 \pm 12$ & $40 \pm 12$ & $39 \pm 10$ & $41 \pm 11$ & $40 \pm 11$ \\
\hline Eosinophil (\%) & $0.6 \pm 0.2$ & $0.5 \pm 0.1$ & $0.2 \pm 0.1$ & $0.1 \pm 0.1$ & $0.2 \pm 0.1$ & $0.7 \pm 0.2$ & $0.1 \pm 0.1$ & $0.1 \pm 0.1$ \\
\hline
\end{tabular}

Values are mean \pm standard deviation. Significance [from linear mixed models]: ${ }^{*} p<0.05,{ }^{* *} p<0.01$ compared to LOW, ${ }^{\#} p<0.05,{ }^{\# \#} p<0.01$ compared to Pre. Total cell count values are presented as number of cells per $\mathrm{mL}$ of spontaneous sputum sample. Differential cell count values are presented as percentage of the total leukocyte cell count. Direction is the return component of bicycle commute trip performance: Inbound = morning, ingress of CBD; Outbound = afternoon, egress of CBD. Time point is relative to bicycle commute trip performance: Pre $=$ immediately pre-commute; Post $=$ three hours post-commute.

been shown to be effective under the circumstances of this study; mean and median PNC was significantly reduced with LOW compared to HIGH, which is in agreement with similar previous research $[6,10,15]$. The observation of the current study that the mean reduction in PNC was largest for the inbound, compared to outbound, commute of HIGH is also in agreement with previous urban measurement studies [37-39]. The reduction of median PNC level was generally smaller (although still significant) in magnitude compared to the reduction of mean PNC level, which suggests a strong influence by in-commute PNC peaks, which can be associated with road crossings and traffic control lights, on total commute PNC exposure. There was no significant difference between LOW inbound and outbound trips, indicating the influence by proximity to motorised traffic on PNC, particularly with the morning peak hour traffic, which is expected to be more time-concentrated than the afternoon peak [37-39].

Previously, in Brisbane, a mean PNC of $7.4 \times \mathrm{e}^{3}$ ppcc and a median PD of $40 \mathrm{~nm}$ (values strongly-associated with motor vehicle emissions) have been shown as background measurements [40]. More recently, PNC in Brisbane has been shown to have increased to a mean of $10.0 \times \mathrm{e}^{3}$ ppcc, and PD decreased to a median of $38 \mathrm{~nm}$, however these levels are relatively-low compared with other cities worldwide [41] and generally do not reflect incommute exposure but background concentrations [42,43]. A meta-analysis performed using 71 UFP studies of different environments showed typical mean PNC of $7.3 \times \mathrm{e}^{3}$ ppcc for urban background and $42.1 \times \mathrm{e}^{3}$ ppcc for roadside measurements, and indicated that higher proximity to motorised traffic is positively-associated with PNC [44]. In the current study, the median PD was not significantly different between HIGH and LOW, nor between inbound and outbound trips within either HIGH or LOW.
That is, a higher mean PNC was not significantly associated with a lower mean PD, and vice versa, suggesting the in-commute measurement of fresh petrol emissions or nucleation events [41].

A recent meta-analysis of UFP exposure in-transit across different modes of transport indicates that cyclists are generally exposed to the lowest PNC of any mode [45]. Studies specifically comparing bicycle commute routes with high and low proximity to motorised traffic have indicated a mean PNC of $3.5 \times \mathrm{e}^{4}$ and $2.6 \times \mathrm{e}^{4}$ ppcc, respectively [45]. In comparison, motor vehicle passengers can be exposed to PNC 1.3 times higher than cyclists $[46,47]$.

\section{Heart rate and physical effort}

As bicycle commuting requires physical exercise, pulmonary ventilation rates of participants can be an important factor when determining the inhaled dose of UFP and therefore a toxic biological interaction. Ventilation rates of cyclists in previous studies have been approximately 2 to 4 times higher than motor vehicle passengers, though this rate is believed to be conservative $[47,48]$. An experiment study showed that particle deposition can be 4.5 times higher during moderate bicycling exercise compared to rest, in healthy individuals [49]. Inhaled mean particle count can be halved by using a pre-determined route alteration of minimal, compared to maximal, proximity to motorised traffic [33], similar to the current study results for mean PNC.

The correlation between heart rate and pulmonary ventilation rate during exercise is high and, while it varies between individuals, a predictable association can be made for an individual once a heart-rate ventilation association equation has been produced [50,51]. The current study did not include exercise testing to provide values for such an equation, however, the intention was to 
make intra-individual comparison of heart rates between route alterations to estimate if inhaled particle count was determined by PNC rather than pulmonary ventilation level. As heart rates were not significantly different between HIGH and LOW, it could be inferred that any potential difference in inhaled particle count would be attributable to differences in PNC rather than physical effort, and therefore ventilation rate, required for HIGH or LOW. A previous study in the same geographical region by the current research group showed that estimated ventilation rates (via heart rate-ventilation association curves produced with exercise testing) were not significantly different between popular bicycle commute routes of low and high proximity to motorised traffic [33].

The mean distance and duration of commutes were not significantly increased from the alteration to LOW from $\mathrm{HIGH}$, therefore not increasing overall exposure to motorised traffic emissions due to an increased exposure period. As commute distance or duration is not increased, the utility of an altered bicycle commute route to lower proximity to motorised traffic emissions has been demonstrated, in this project, as practical for individuals rating time as an important feature of a commute route.

\section{Climate variation}

In the current project, the measured meteorological variables were not significantly different between HIGH and LOW. The diurnal variation of climate potentially produced a higher mean temperature and lower mean humidity for the outbound (afternoon), compared to the inbound (morning), commute. The influence that these differences in temperature and humidity have when comparing air quality measures of $\mathrm{HIGH}$ and LOW is negligible as inbound and outbound trips were performed in equal measure for $\mathrm{HIGH}$ and LOW. The significantly-higher $\mathrm{PNC}$ in $\mathrm{HIGH}$ inbound compared to HIGH outbound could be attributable to nucleation inhibition occuring in the HIGH outbound (afternoon) with the circumstances of higher temperature and lower humidity [52]. Previous study conditions of lower temperature and higher humidity have been shown to produce secondary particle production and an increase in PNC [53-56], such as the circumstances in the $\mathrm{HIGH}$ inbound (morning) commute in the current project.

\section{Air quality detection}

The association of air pollution exposure perception and symptoms during active transport has had limited attention in previous research. In the current project, the detection of offensive odours and particles, dust and soot was higher in-commute for HIGH compared to LOW, which was generally similar to actual air quality (indicated by the mean PNC). Previously, odorous traffic fumes and visible dust or soot annoyed community members despite pollutant levels being compliant with current World Health Organisation (WHO) recommendations, and irritation of the eyes was significantly associated with respondent rating of air quality [57]. The adequate perception of in-commute air quality, via the detection of offensive odours and particles, dust or soot, could assist individuals to re-consider their commute route to decrease exposure (as this study has found to be effective) when and where appropriate.

\section{Physiological inflammatory response}

In the current project, in conjunction with the significantly higher PNC for HIGH compared to LOW, there was an increase in offensive odour detection and nasal irritation, but no acute respiratory symptoms were increased immediately-post-commute and three-hourspost-commute. While personal $\mathrm{NO}_{\mathrm{X}}$ exposure was not monitored, it is probable that $\mathrm{NO}_{\mathrm{X}}$ concentrations were substantially higher with HIGH compared to LOW due to the strong association of $\mathrm{NO}_{\mathrm{X}}$ to motorised traffic emissions and particle number [58]. However, despite an increased offensive odour detection with HIGH compared to LOW, acute respiratory symptoms that may be associated with elevated $\mathrm{NO}_{\mathrm{X}}$ exposure concentrations (including nasopharyngeal irritation, dyspnoea and tussis; observed previously with research of indoor air quality [59]) were not increased post-commute or decreased for LOW compared to HIGH.

In the current project there was no significant change in peak expiratory flow rate or neutrophil counts, either pre-commute to post-commute or in LOW compared to HIGH. Previously, healthy and asthmatic adults exposed to a mean PNC of $1.45 \times \mathrm{e}^{5}$ ppcc during 2 hours of intermittent exercise did not exhibit significant differences in sputum neutrophil counts immediately or four hours post-exposure [27]. Similarly, healthy and asthmatic adults exposed to a mean PNC of $4.77 \times \mathrm{e}^{6}$ ppcc during rest and exercise did not have significant differences in respiratory symptoms or sputum neutrophil counts, however did have a reduction in maximal midexpiratory flow rate twenty-one hours post-exposure [4].

While the results of this project did not indicate any acute health effects from the variables measured, the PNC exposure levels $\left(\mathrm{HIGH}=3.3 \times \mathrm{e}^{4}\right.$ ppcc, $\sim 40 \mathrm{mins}$ and LOW $=1.8 \times \mathrm{e}^{4}$ ppcc, $\sim 40 \mathrm{mins}$ ) surpass previous levels observed to increase systemic markers of inflammation in healthy individuals exercising intermittently for a longer duration (1.1 $\times \mathrm{e}^{4}$ ppcc, $\left.120 \mathrm{mins}\right)$ [60]. Exposure at higher levels of UFP and for longer durations than the current project has elicited increases in lower airway inflammatory mediators [61] and systemic markers of inflammation [28], oxidative DNA damage [43], and decreased lung function from airway inflammation [6]. Therefore, it is reasonable that the mean PNC exposure 
levels and durations for HIGH and LOW were too low to significantly affect the specific acute health variables measured in the current project.

Sputum neutrophils, obtained from the lower airways, have been used previously as a biomarker for airway inflammation, but these cells can have a low association with lung function and respiratory symptoms [20]. The utility of repeated sputum induction on cell counts over a 24-hour period has been questioned [62]. One project has shown no significant changes in sputum cell differential counts for healthy individuals in response to $\mathrm{PNC}$ exposure during rest and exercise ( $\leq 6.9 \times \mathrm{e}^{6}$ ppcc, 120 mins). However, in asthmatics following a similar protocol, PNC was associated with a significant increase in alveolar macrophages by $11 \%$ compared to filtered air [4]. A physiological inflammatory response was not indicated in the current project as there was no significant change in neutrophil count.

Significant effects of UFP exposure on symptoms, pulmonary function, and markers of airway or systemic inflammation are not yet confirmed [63]. The mechanisms of these effects for inhaled UFP are not yet known, but these particles have significantly higher pulmonary inflammatory effects compared to coarser particles at equal mass dose $[7,45,64]$. Regardless, the strategy of altering a bicycle commute route to lower proximity to motorised traffic continues to be shown as effective at substantially reducing exposure to vehicle-emitted air pollution such as UFP, even if evidence of a healthprotective advantage in healthy individuals has currently not yet been determined [65].

\section{Participant preference of commute alteration}

Previous research by the current research group showed that a large cohort $(n=155)$ of frequent inner-city bicycle commuters would consider re-routing their commute to lower proximity to motorised traffic, if this was proven to be an appropriate and effective risk management strategy and dependent on route factors of safety (i.e. greater riding space or visibility) as well as time (i.e. duration of commute) [22]. Off-road routes allow a reduction of the proximity to motorised traffic and thus improved physical safety (along with reduced air pollution exposure risk), but these routes are typically less direct and take a longer time to complete. However, this was not the case in this study, as commute distance and duration were not affected by the alteration of the commute route to lower proximity to motorised traffic. The participants of the current study typically used a bicycle commute route of high proximity to motorised traffic, and some preferred their typical route (deemed as HIGH) compared to LOW after participation in this study, due primarily to the component of time. Conversely, LOW was preferred over HIGH by most participants due to reasons of health (that is, to avoid air pollution) and safety of the participant. Therefore, the development of appropriate infrastructure and educational schemes would be desirable to implement a sustainable bicycle commuting environment, to assist an individual to manage their own air pollution exposure risk, as necessary.

\section{Limitations}

At the time of conducting this project, the personal UFP monitor used was novel for field research and therefore precedent references were not available, however, previous similar field research [33], personal monitoring of children [66] and device inter-comparison laboratory testing [67] has now been published. In the current project, device correction factors for the monitors used were obtained in controlled conditions against a standard device (see Methods), and the data observed was accepted to be valid. The design of a unique questionnaire (such as that used for symptom reporting in the current project) without a precedent model available for reference will include a factor of unknown validity and reliability. As the questionnaire was self-administered, respondent misunderstandings could have occurred due to question misinterpretation. Questionnaire response measurement error could have resulted as participants could not be blinded to the routes of HIGH or LOW expected decreased. The performance of peak flow measuring and spontaneous sputum sampling were dependent on participant competence and therefore could include measurement error. Verbal and written instructions were provided to participants at induction (see Additional file 1), but field performance was not supervised and therefore cannot be validated; however, specific post-completion quality controls were used (see relevant sub-sections in Methods).

\section{Conclusions}

Exposure to ultrafine particles, typically associated with combustion emissions of motorised traffic, can be significantly reduced by lowering proximity to motorised traffic without significantly increasing commute distance or duration whilst bicycle commuting. Regulatory authorities encouraging bicycle commuting participation should educate participants in air quality and risk management, and also ensure practical consideration when creating bicycle commuting routes, to maximise participation rates yet minimise any health risk consequent to chronic, frequent in-commute exposure to motorised traffic emissions.

\section{Additional files}

Additional file 1: Participant Instructions.

Additional file 2: Participant checklist \& data sheet (per day / return trip). 


\section{Abbreviations}

CBD: Central business district; CPC: Condensation particle counter; PEF: Peak expiratory flow; PD: Particle diameter; PM: Particulate matter; PNC: Particle number concentration; ppcc: Particles per cubic centimetre; UFP: Ultrafine particle.

\section{Competing interests}

The authors declare that they have no competing interests.

\section{Authors' contributions}

TCH conceived and designed the study, recruited participants, collected and analysed all data and drafted the manuscript; LM supervised study design, exposure data collection and analysis, and manuscript revision; IS supervised study design, clinical data analysis, and manuscript revision; $\mathrm{MH}$ assisted with study design, and clinical data collection and procession; RJ supervised study design, exposure data collection, and data analysis and manuscript production and revision; CS assisted and/or supervised study design, clinical data collection and procession, exposure data collection, data analysis and manuscript revision. All authors read and approved the final manuscript.

\section{Acknowledgements}

We thank all participants for their enthusiasm towards involvement in this project. Further, we thank Ms Camilla Tuttle for detailed guidance with laboratory procedures, and Dr Dimitrios Vagenas for his patient help with statistical analyses.

\section{Author details}

'Institute of Health and Biomedical Innovation, Queensland University of Technology, 60 Musk Avenue, Brisbane, QLD 4059, Australia. ${ }^{2}$ International Laboratory for Air Quality and Health, Queensland University of Technology, 2 George Street, Brisbane, QLD 4001, Australia. ${ }^{3}$ School of Life Sciences, Queensland University of Technology, 2 George Street, Brisbane, QLD 4001, Australia. ${ }^{4}$ School of Health and Sport Sciences, University of the Sunshine Coast, Sippy Downs Drive, Sippy Downs, QLD 4556, Australia.

Received: 10 July 2012 Accepted: 19 March 2013

Published: 8 April 2013

\section{References}

1. Blair SN, Morris JN: Healthy hearts-and the universal benefits of being physically active: Physical activity and health. Ann Epidemiol 2009, 19:253-256.

2. Shiroma EJ, Lee I: Physical activity and cardiovascular health: lessons learned from epidemiological studies across age, gender, and race/ ethnicity. Circulation 2010, 122:743.

3. Warburton DER, Nicol CW, Bredin SSD: Health benefits of physical activity: the evidence. Can Med Assoc J 2006, 174:801.

4. Pietropaoli AP, Frampton MW, Hyde RW, Morrow PE, Oberdörster G, Cox C Speers DM, Frasier LM, Chalupa DC, Huang LS: Pulmonary function, diffusing capacity, and inflammation in healthy and asthmatic subjects exposed to ultrafine particles. Inhal Toxicol 2004, 16:59-72.

5. Atkinson RW, Carey IM, Kent AJ, van Staa TP, Anderson HR, Cook DG: Long-term exposure to outdoor air pollution and incidence of cardiovascular diseases. Epidemiology 2013, 24:44-53.

6. Strak M, Boogaard H, Meliefste $K$, Oldenwening $M$, Zuurbier $M$, Brunekreef $B$, Hoek G: Respiratory health effects of ultrafine and fine particle exposure in cyclists. Occup Environ Med 2010, 67:118.

7. Singh S, Shi T, Duffin R, Albrecht C, van Berlo D, Höhr D, Fubini B, Martra G, Fenoglio I, Borm PJA, Schins RPF: Endocytosis, oxidative stress and IL-8 expression in human lung epithelial cells upon treatment with fine and ultrafine $\mathrm{TiO}_{2}$ : Role of the specific surface area and of surface methylation of the particles. Toxicol Appl Pharmacol 2007, 222:141-151.

8. de Hartog J, Boogaard H, Nijland H, Hoek G: Do the health benefits of cycling outweigh the risks? Environ Health Perspect 2010, 118:1109.

9. Rabl A, de Nazelle A: Benefits of shift from car to active transport. Transport Policy 2012, 19:121-131.

10. Zuurbier M, Hoek G, Oldenwening M, Lenters V, Meliefste K, Van Den Hazel P, Brunekreef B: Commuters' Exposure to particulate matter Air pollution is affected by mode of transport, fuel type, and route. Environ Health Perspect 2010, 118:783.
11. Rojas-Rueda D, de Nazelle A, Tainio M, Nieuwenhuijsen MJ: The health risks and benefits of cycling in urban environments compared with car use: health impact assessment study. $\mathrm{Br}$ Med J 2011, 343:d4521.

12. Giles LV, Barn P, Künzli N, Romieu I, Mittleman MA, van Eeden S, Allen R, Carlsten C, Stieb D, Noonan C: From good intentions to proven interventions: effectiveness of actions to reduce the health impacts of air pollution. Environ Health Perspect 2011, 119:29.

13. Hertel O, Hvidberg M, Ketzel M, Storm L, Stausgaard L: A proper choice of route significantly reduces air pollution exposure-A study on bicycle and bus trips in urban streets. Sci Total Environ 2008, 389:58-70.

14. Kaur S, Nieuwenhuijsen M, Colvile R: Personal exposure of street canyon intersection users to PM2. 5, ultrafine particle counts and carbon monoxide in Central London, UK. Atmos Environ 2005, 39:3629-3641.

15. Pattinson W: Cyclist exposure to traffic pollution: microscale variance, the impact of route choice and comparisons to other modal choices in two New Zealand cities. Christchurch, New Zealand: University of Canterbury; 2009.

16. Thai A, McKendry I, Brauer M: Particulate matter exposure along designated bicycle routes in Vancouver, British Columbia. Sci Total Environ 2008, 405:26-35.

17. Wåhlin $P$, Palmgren F, Van Dingenen R: Experimental studies of ultrafine particles in streets and the relationship to traffic. Atmos Environ 2001, 35:63-69.

18. Nightingale JA, Maggs R, Cullinan P, Donnelly LE, Rogers DF, Kinnersley R, Fan Chung K, Barnes PJ, Ashmore M, Newman-Taylor A: Airway inflammation after controlled exposure to diesel exhaust particulates. Am J Respir Crit Care Med 2000, 162:161-166.

19. Nordenhäll C, Pourazar J, Blomberg A, Levin JO, Sandström T, Ädelroth E: Airway inflammation following exposure to diesel exhaust: a study of time kinetics using induced sputum. Eur Respir J 2000, 15:1046-1051.

20. Singh D, Edwards L, Tal-Singer R, Rennard S: Research Sputum neutrophils as a biomarker in COPD: findings from the ECLIPSE study vol. 11. BioMed Central: Respiratory Research; 2010:77-89.

21. World Health Organisation: Global Database on Body Mass Index. Geneva, Switzerland: World Health Organisation; 2012.

22. Cole-Hunter T, Morawska L, Solomon C: Air pollution exposure in adult bicycle commuters: a questionnaire-based investigation of exposure potentials, perceptions, symptoms and risk management strategies, $\mathrm{PhD}$ Thesis. Brisbane, Australia: Queensland University of Technology; 2012.

23. Badland HM, Duncan MJ: Perceptions of air pollution during the workrelated commute by adults in Queensland, Australia. Atmos Environ 2009, 43:5791-5795.

24. Kjærgaard T, Cvancarova M, Steinsvåg SK: Cigarette smoking and self-assessed upper airway health. Eur Arch Otorhinolanyngol 2011, 268:219-226.

25. American Thoracic Society: What constitutes an adverse health effect of air pollution? Am J Respir Crit Care Med 2000, 161:665-673.

26. Stanek LW, Brown JS, Stanek J, Gift J, Costa DL: Air pollution toxicology —a brief review of the role of the science in shaping the current understanding of Air pollution health risks. Toxicol Sci 2011, 120:S8.

27. Gong H Jr, Linn WS, Clark KW, Anderson KR, Sioutas C, Alexis NE, Cascio WE, Devlin RB: Exposures of healthy and asthmatic volunteers to concentrated ambient ultrafine particles in Los Angeles. Inhal Toxicol 2008, 20:533-545.

28. Jacobs L, Nawrot T, de Geus B, Meeusen R, Degraeuwe B, Bernard A, Sughis M, Nemery B, Panis L: Subclinical responses in healthy cyclists briefly exposed to traffic-related air pollution: an intervention study. Environ Heal 2010, 9:64.

29. Australian Bureau of Meteorology: Climate Data Online. 2011. http://www. bom.gov.au/climate/data/.

30. Australia Bureau of Statistics: Regional Population Growth, Australia, 2009-10. Canberra, Australia: Australian Federal Government; 2011.

31. Department of Transport and Main Roads: Vehicles on Register in Queensland's South East Region. Brisbane, Australia: Queensland State Government; 2011.

32. Marra J, Den Brink W, Goossens H, Kessels S: Nanoparticle monitoring for exposure assessment. Nanotechnol Mag, IEEE 2009, 3:6-37.

33. Cole-Hunter T, Morawska L, Stewart I, Jayaratne J, Solomon C: Inhaled particle counts on bicycle commute routes of low and high proximity to motorised traffic. Atmos Environ 2012, 61:197-203.

34. Puustinen A, Hämeri K, Pekkanen J, Kulmala M, de Hartog J, Meliefste K, ten Brink H, Kos G, Katsouyanni K, Karakatsani A: Spatial variation of 
particle number and mass over four European cities. Atmos Environ 2007, 41:6622-6636.

35. Mermier CM, Samet JM, Lambert WE, Chick TW: Evaluation of the relationship between heart rate and ventilation for epidemiologic studies. Arch Environ Health: An International Journal 1993, 48:263-269.

36. Belda J, Leigh R, Parameswaran K, O'Byrne PM, Sears MR, Hargreave FE: Induced sputum cell counts in healthy adults. Am J Respir Crit Care Med 2000, 161:475

37. Molnár $P$, Janhäll $S$, Hallquist M: Roadside measurements of fine and ultrafine particles at a major road north of Gothenburg. Atmos Environ 2002, 36:4115-4123.

38. Weichenthal S, Dufresne A, Infante-Rivard C, Joseph L: Determinants of ultrafine particle exposures in transportation environments: findings of an 8-month survey conducted in Montreal, Canada. J Expo Sci Environ Epidemiol 2008, 18:551-563.

39. Karellas N, Whitelaw C, Debosz J, Stacey N: Ultrafine Particle Measurements in Real Time at an Urban Site in Ontario. Orlando, USA: American Association for Aerosol Research and PublisherLocation is AAAR 30th Annual Conference; 2011.

40. Morawska L, Thomas S, Bofinger N, Wainwright D, Neale D: Comprehensive characterization of aerosols in a subtropical urban atmosphere: particle size distribution and correlation with gaseous pollutants. Atmos Environ 1998, 32:2467-2478.

41. Mejıa J, Morawska L, Mengersen K: Spatial variation in particle number size distributions in a large metropolitan area. Atmos Chem Phys 2008, 8:1127-1138.

42. Kaur S, Nieuwenhuijsen M, Colvile R: Fine particulate matter and carbon monoxide exposure concentrations in urban street transport microenvironments. Atmos Environ 2007, 41:4781-4810.

43. Vinzents $P$, Møller $P$, Sørensen M, Knudsen L, Hertel O, Jensen F, Schibye B, Loft S: Personal exposure to ultrafine particles and oxidative DNA damage. Environ Health Perspect 2005, 113:1485.

44. Morawska L, Ristovski Z, Jayaratne E, Keogh DU, Ling X: Ambient nano and ultrafine particles from motor vehicle emissions: Characteristics, ambient processing and implications on human exposure. Atmos Environ 2008, 42:8113-8138

45. Knibbs LD, Cole-Hunter T, Morawska L: A review of commuter exposure to ultrafine particles and its health effects. Atmos Environ 2011, 45:2611-2622.

46. Boogaard H, Borgman F, Kamminga J, Hoek G: Exposure to ultrafine and fine particles and noise during cycling and driving in 11 Dutch cities. Atmos Environ 2009, 43:4234-4242.

47. Int Panis L, de Geus B, Vandenbulcke G, Willems H, Degraeuwe B, Bleux N, Mishra V, Thomas I, Meeusen R: Exposure to particulate matter in traffic: A comparison of cyclists and car passengers. Atmos Environ 2010, 44:2263-2270

48. van Wijnen J, Verhoetf A, Jans $H$, van Bruggen M: Exposure of cyclists, car drivers and pedestrians to motor vehicle exhaust emissions. Epidemiology 1995, 6:S25

49. Daigle CC, Chalupa DC, Gibb FR, Morrow PE, Oberdörster G, Utell MJ, Frampton MW: Ultrafine particle deposition in humans during rest and exercise. Inhal Toxicol 2003, 15:539-552.

50. Vai F, Bonnet J, Ritter P, Pioger G: Relationship between heart rate and minute ventilation, tidal volume and respiratory rate during brief and low level exercise. Pacing Clin Electrophysiol 1988, 11:1860-1865.

51. Treese N, MacCarter D, Akbulut O, Coutinho M, Baez M, Liebrich A, Meyer J: Ventilation and heart rate response during exercise in normals: Relevance for rate variable pacing. Pacing Clin Electrophysiol 1993, 16:1693-1700

52. Kulmala M, Vehkamäki H, Petäjä T, Dal Maso M, Lauri A, Kerminen VM, Birmili W, McMurry P: Formation and growth rates of ultrafine atmospheric particles: a review of observations. Journal of Aerosol Science 2004, 35:143-176.

53. Holmes NS: A review of particle formation events and growth in the atmosphere in the various environments and discussion of mechanistic implications. Atmos Environ 2007, 41:2183-2201.

54. Jeong $\mathrm{CH}$, Hopke PK, Chalupa D, Utell M: Characteristics of nucleation and growth events of ultrafine particles measured in Rochester, NY. Environ Sci Technol 2004, 38:1933-1940.
55. Kaur S, Nieuwenhuijsen M: Determinants of personal exposure to PM2. 5 , ultrafine particle counts, and $\mathrm{CO}$ in a transport microenvironment. Environ Sci Technol 2009, 43:4737-4743.

56. Jamriska M, Morawska L, Mergersen $\mathrm{K}$ : The effect of temperature and humidity on size segregated traffic exhaust particle emissions. Atmos Environ 2008, 42:2369-2382.

57. Lercher $P$, Schmitzberger R, Kofler W: Perceived traffic air pollution, associated behavior and health in an alpine area. Sci Total Environ 1995, 169:71-74.

58. Ayoko G, Jamriska M, Jayaratne R, Morawska L: Air pollution levels measured at traffic hot spots: Brisbane urban corridor study. In 2005: CASANZ. New Zealand: Clean Air Society of Australia; 2005:1-7.

59. Lee K, Yanagisawa Y, Spengler JD, Nakai S: Carbon monoxide and nitrogen dioxide exposures in indoor ice skating rinks. J Sports Sci 1994, 12:279-279.

60. Nyström AK, Svartengren M, Grunewald J, Pousette C, Rödin I, Lundin A, Sköld CM, Eklund A, Larsson BM: Health effects of a subway environment in healthy volunteers. Eur Respir J 2010, 36:240-248.

61. Larsson B, Sehlstedt M, Grunewald J, Sköld C, Lundin A, Blomberg A, Sandström T, Eklund A, Svartengren M: Road tunnel air pollution induces bronchoalveolar inflammation in healthy subjects. Eur Respir J 2007, 29:699.

62. Nightingale JA, Rogers DF, Barnes PJ: Effect of repeated sputum induction on cell counts in normal volunteers. Thorax 1998, 53:87.

63. Frampton MW, Utell MJ, Zareba W, Oberdörster G, Cox C, Huang LS, Morrow PE, Lee FE, Chalupa D, Frasier LM: Effects of exposure to ultrafine carbon particles in healthy subjects and subjects with asthma. Res Rep Health Eff Inst 2004, 126:1.

64. Oberdörster $G$, Oberdörster E, Oberdörster J: Nanotoxicology: an emerging discipline evolving from studies of ultrafine particles. Environ Health Perspect 2005, 113:823.

65. Jarjour S, Jerrett M, Westerdahl D, Nazelle A, Hanning C, Daly L, Lipsitt J, Balmes J: Cyclist route choice, traffic-related air pollution, and lung function: a scripted exposure study. Environ Heal 2013, 12:14.

66. Buonanno G, Marini S, Morawska L, Fuoco FC: Individual dose and exposure of Italian children to ultrafine particles. Sci Total Environ 2012, 438:271-277.

67. Asbach C, Kaminski H, Von Barany D, Kuhlbusch TA, Monz C, Dziurowitz N, Pelzer J, Vossen K, Berlin K, Dietrich S, Gotz U, Kiesling HJ, Schierl R, Dahmann D: Comparability of portable nanoparticle exposure monitors. Ann Occup Hyg 2012, 56:606-621.

\section{doi:10.1186/1476-069X-12-29}

Cite this article as: Cole-Hunter et al.: Utility of an alternative bicycle commute route of lower proximity to motorised traffic in decreasing exposure to ultra-fine particles, respiratory symptoms and airway inflammation - a structured exposure experiment. Environmental Health 2013 12:29.

\section{Submit your next manuscript to BioMed Central and take full advantage of:}

- Convenient online submission

- Thorough peer review

- No space constraints or color figure charges

- Immediate publication on acceptance

- Inclusion in PubMed, CAS, Scopus and Google Scholar

- Research which is freely available for redistribution 